University of Nebraska - Lincoln

DigitalCommons@University of Nebraska - Lincoln

USDA National Wildlife Research Center - Staff Publications
U.S. Department of Agriculture: Animal and Plant Health Inspection Service

March 2002

\title{
High-performance liquid chromatography-based determination of nicarbazin excretion in waterfowl
}

\author{
Randal S. Stahl \\ USDA-APHIS-Wildlife Services, randal.s.stahl@aphis.usda.gov \\ John J. Johnston \\ National Wildlife Research Center, USDA/APHIS
}

Follow this and additional works at: https://digitalcommons.unl.edu/icwdm_usdanwrc

Part of the Environmental Sciences Commons

Stahl, Randal S. and Johnston, John J., "High-performance liquid chromatography-based determination of nicarbazin excretion in waterfowl" (2002). USDA National Wildlife Research Center - Staff Publications. 669.

https://digitalcommons.unl.edu/icwdm_usdanwrc/669

This Article is brought to you for free and open access by the U.S. Department of Agriculture: Animal and Plant Health Inspection Service at DigitalCommons@University of Nebraska - Lincoln. It has been accepted for inclusion in USDA National Wildlife Research Center - Staff Publications by an authorized administrator of DigitalCommons@University of Nebraska - Lincoln. 


\title{
Short communication
}

\section{High-performance liquid chromatography-based determination of nicarbazin excretion in waterfowl}

\author{
Randal S. Stahl*, John J. Johnston \\ National Wildlife Research Center, USDA/APHIS, 4101 La Porte Avenue, Fort Collins, CO 99801, USA
}

Received 18 September 2001; received in revised form 5 March 2002; accepted 20 March 2002

\begin{abstract}
A method for the high-performance liquid chromatography (HPLC) determination of nicarbazin uptake and excretion in ducks is presented. The method uses few clean-up steps and provides a rapid assessment of nicarbazin excretion by measuring the analyte 4,4'-dinitrocarbanalide (DNC). During method development the effect of extraction volume, number of extractions, mobile phase composition, column temperature, and injection volume were varied to optimize sensitivity and

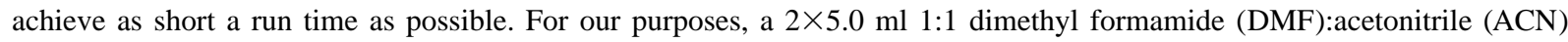
extraction injected $(40 \mathrm{ml})$ into an HPLC system equipped with a Keystone octadecylsilyl (ODS) $\mathrm{C}_{18}$ column and a UV variable wavelength detector $(\lambda=347 \mathrm{~nm})$ with a mobile phase of 60:40 (v/v) ACN- $\mathrm{H}_{2} \mathrm{O}$, at a flow-rate of $1.0 \mathrm{ml} / \mathrm{min}$ at a column temperature of $35^{\circ} \mathrm{C}$ provided adequate resolution and an acceptable total run time. Studies conducted during method development for inter-day recovery efficiencies for $0.46,1.8$ and $88.5 \mu \mathrm{g} / \mathrm{g}$ fortified samples $(n=3)$ had mean recoveries of 91, 94 and $97 \%$ and intra-day $(n=3)$ recoveries at the same fortification levels of 103, 94, and 92\%. The method has been used successfully in excretion studies of nicarbazin in ducks. (C) 2002 Published by Elsevier Science B.V.
\end{abstract}

Keywords: Nicarbazin

\section{Introduction}

Nicarbazin is widely used as a coccidiostat in poultry in the US and Europe. It is used primarily to control protozoa (Eimeria sp.) in broiler chicken (poultry raised to market the carcass) production [1]. Nicarbazin is an equal molar complex of $4,4^{\prime}$-dinitrocarbanalide (DNC; Fig. 1) and 2-hydroxy-4,6dimethylpyrimidine (HDP; Fig. 1). When nicarbazin is given to layers (poultry raised to market eggs) it reduces egg production, egg weight, hatchability, and

\footnotetext{
*Corresponding author. Tel.: +1-970-266-6062; fax: + 1-970266-6063.
}

shell pigmentation. These effects, particularly the reduction in hatchability, have made nicarbazin the subject of a research program to evaluate its effectiveness as an oral contraceptive in waterfowl.

Numerous methodologies exist in the literature for monitoring nicarbazin related residues, primarily as the DNC marker, in the tissues and eggs of poultry [1-8] or in feeds [9-11]. The nicarbazin concentration in poultry litter has also been determined [2]. The majority of these methods utilize an organic extraction, followed by a clean-up step using liquid/ liquid or solid-phase extraction prior to analyzing with high-performance liquid chromatography with UV detection (HPLC-UV) or high-performance 
<smiles>O=C(Nc1ccc([N+](=O)[O-])cc1)Nc1ccc([N+](=O)[O-])cc1</smiles>

A. 4,4' Dinitrocarbanalide (DNC)<smiles>Cc1cc(C)nc(O)n1</smiles>

\section{B. 4,6 dimethyl-2-pyrimidinol (HDP)}

Fig. 1. The structures of 4,4'-dinitrocarbanalide (DNC) and 2hydroxy-4,6-dimethylpyrimidine (HDP).

liquid chromatography-electron ionization-mass spectroscopy (HPLC-EI-MS). The number of steps in these processes often results in poor recovery and the number of steps in these procedures imposes a severe limitation with respect to sample throughput; this is a significant concern when it is necessary to screen a large number of samples in a short period of time.

The present study describes a method using an organic extraction of the feces followed by determination of the concentration in the extract using reversed-phase high-performance liquid chromatography with minimal clean-up. The method was validated for fortified feces samples containing DNC from 0.5 to $100 \mu \mathrm{g} / \mathrm{g}$. The method is rapid and allows for the monitoring of dietary uptake and excretion of nicarbazin in treated waterfowl. The method has been successfully applied to feeding/ excretion studies of nicarbazin in Mallard ducks (Anas platyrhyncos).

\section{Experimental}

Reagents: All solvents were LC grade unless otherwise noted. Acetonitrile (ACN) and dimethylformamide (DMF) were obtained from Fisher Sci- entific (Fair Lawn, NJ, USA). DNC (96.6\%) was obtained from Koffolk Ltd. (Rancho Sante Fe, CA, USA). Water was distilled in house.

A standard stock solution was prepared by dissolving DNC $(1000 \mu \mathrm{g} / \mathrm{ml})$ in DMF. The stock solution was sonicated for $15 \mathrm{~min}$. Three dilute stock solutions were prepared from the $1000 \mu \mathrm{g} / \mathrm{ml}$ stock solutions in DMF at concentrations of 100, 10 and 1 $\mu \mathrm{g} / \mathrm{ml}$. These were used to prepare standards over the range of 0.05 to $20 \mu \mathrm{g} / \mathrm{ml}$ by diluting the stock solution in ACN-DMF-water (45:45:10, v/v). All stock and standard solutions were stored in the dark at $4{ }^{\circ} \mathrm{C}$ and were stable for 1 month. The 1000 and $10 \mu \mathrm{g} / \mathrm{ml}$ stock DNC solutions in DMF were used to fortify samples.

Equipment: A Fisher Centrific centrifuge (Pittsburgh, PA, USA), a Bransonic 32 Sonicator (Branson Cleaning Equipment Co., Shelton, CT, USA) and an Eberbach mechanical shaker (Eberbach Corp., Ann Arbor, MI, USA) were used during the extraction of the samples. Samples were filtered with a $0.45 \mu$ Teflon filter (Fisherbrand, Fisher Scientific, Pittsburgh, PA, USA) prior to HPLC analysis. LC vials were obtained from Agilent (Palo Alto, CA, USA).

\section{Chromatography}

Samples were run on a Hewlett-Packard Series 1050 HPLC which consisted of a quaternary pump HP1050, and automatic injector HP1050, a thermal control module HP1050 and a variable UV wavelength detector HP1050. The system was interfaced via a GPIB interface to a Hewlett-Packard Vectra $\mathrm{X} / \mathrm{M}$ Series 4-5/150 computer running HewlettPackard Chemstation software. Samples were separated on a $250 \times 4.6 \mathrm{~mm}$ Keystone ODS/H C 18 (5 $\mu \mathrm{m}$ particle size) column (Keystone, Bellfonte, PA, USA). A Keystone $4.6 \mathrm{~mm}$ ODS/H guard column was used. The effect of column with temperature was investigated across the range of $20-40{ }^{\circ} \mathrm{C}$, and samples were detected with a UV detector at $\lambda=347$ $\mathrm{nm}$. Mobile phase was acetonitrile:water. The elution was isocratic and mixtures evaluated were 60:40, 65:35 and 70:30 (v/v) acetonitrile-water. $\mathrm{MeOH}$ was considered but dropped due to very poor peak shape. Injection volumes of 20, 40, 50, 60 and 100 $\mathrm{ml}$ were investigated for effect on peak shape and peak height. 


\section{Sample preparation}

Duck feces were collected from birds maintained in a controlled environment facility at the USDA/ APHIS/National Wildlife Research Center, Fort Collins, CO, USA. The control feces were composited from 24 birds. Fecal samples were homogenized by stirring with a spatula. Samples were frozen and stored at $-15{ }^{\circ} \mathrm{C}$ until extracted. Treated bird fecal samples were not composited.

\section{Sample extraction}

The method was developed to support feeding studies where birds were provided feed containing nicarbazin at levels ranging up to $500 \mu \mathrm{g} / \mathrm{g}$. Early fecal samples provided for analysis were small and an initial sample mass of $0.2 \mathrm{~g}$ was investigated. This was increased and sample masses of 0.5, 1.0 and 3.0 $\mathrm{g}$ were extracted for comparison. All extractions were in 1:1 DMF-ACN. Due to the high levels of DNC anticipated in the samples large volumes were initially used.

Volumes were decreased to increase concentrations in the final extract. The number of extractions was decreased to save time. Extractions of $3 \times 10.0$, $3 \times 7.0$ and $2 \times 5.0 \mathrm{ml}$ with final volumes of 50.00 , 25.00 and $10.00 \mathrm{ml}$, respectively, were evaluated.

$N=3$ fecal samples (wet weight), were extracted with a given volume of a $1: 1(\mathrm{v} / \mathrm{v})$ solution of ACN-DMF. The mixture was shaken on a horizontal shaker for 10 min with an oscillation rate of 250 strokes $/ \mathrm{min}$. The sample was then centrifuged for 5 $\min$ at $1470 \times g$. The solution was transferred to a volumetric flask. The extraction was repeated. The extracts were combined and the solution was brought to a final total volume. An aliquot was filtered with a $0.45 \mu \mathrm{m}$ Teflon filter into an LC vial and capped immediately prior to HPLC analysis.

\section{Method validation}

The method was validated by determining linearity at $0.05,0.1,0.5,1.0,5.0,10.0,15.0$, and $20 \mu \mathrm{g} / \mathrm{ml}$ DNC for two separate sets of standard solutions. The method was evaluated for inter $(N=3)$ and intra-day
$(N=3)$ recovery efficiency using fortified fecal material at concentrations of $0.42,1.6$ and $81.7 \mu \mathrm{g} / \mathrm{g}$ DNC.

\section{Results and discussion}

\subsection{Extraction and HPLC optimization}

The total mass of sample extracted, the volumes of extractant used, and the number of extractions per sample were investigated while developing the method. Due to the heterogeneous nature of feces as a sample matrix the need to obtain and analyze a representative sample was a significant concern. Early samples provided were small limiting sample size to less than $0.5 \mathrm{~g}$. Samples smaller than $1 \mathrm{~g}$ were found to have poor repeatability. Samples larger than $1 \mathrm{~g}$ were often unavailable. A sample size of $1 \mathrm{~g}$ was selected as optimal given the constraints imposed by collecting samples in the field and adequate representation of the sample.

Birds being fed the treated bait were exposed to concentrations as high as $500 \mu \mathrm{g} / \mathrm{g}$ DNC. Work with poultry indicated that the material had low residence time and was rapidly excreted [12]. Anticipating high levels in the feces, relatively large extraction volumes of $10.0 \mathrm{ml}$ were used. Analysis of a random selection of fecal samples indicated that this level was not necessary and the extraction volume was decreased to $7.0 \mathrm{ml}$. Mobile phase composition and injection volume were extensively studied with samples 0.5 or $1.0 \mathrm{~g}$ being extracted $3 \times$ 's with 7.0 $\mathrm{ml}$ 1:1 ACN-DMF, brought to a final volume of $25.00 \mathrm{ml}$.

For comparative purposes, the results from three different studies using three replicate feces samples fortified at approximately $100 \mu \mathrm{g} / \mathrm{g}$ under different sample mass, extraction volume, mobile phase are presented in Table 1. All permutations of temperature, mobile phase composition, injection volume and flow-rate investigated are not presented for brevity. All values were collected with a flow-rate of $1 \mathrm{ml} / \mathrm{min}, \lambda=347 \mathrm{~nm}$. Decreasing total extraction volume, greatly increased peak area. At a given mobile phase composition, smaller injection volumes improved peak width and peak shape. Increasing the mobile phase composition from 60:40 to $70: 30$ 
Table 1

Comparison of three different study procedures for the determination of DNC concentration in fortified duck fecal samples

\begin{tabular}{|c|c|c|c|}
\hline \multirow[b]{2}{*}{ Mobile phase $\% \mathrm{ACN}: \% \mathrm{H}_{2} \mathrm{O}$} & \multicolumn{3}{|c|}{ Study parameters } \\
\hline & $60: 40$ & $60: 40$ & $70: 30$ \\
\hline Extraction volume (ml) & 7.0 & 5.0 & 5.0 \\
\hline Number of extractions & 3 & 2 & 2 \\
\hline Total extraction & 25.00 & 10.00 & 10.00 \\
\hline \multicolumn{4}{|l|}{ Volume (ml) } \\
\hline Sample mass (g) & $0.22 \pm 0.01$ & $1.00 \pm 0.05$ & $1.00 \pm 0.05$ \\
\hline Fortification & $97.4 \pm 4.7$ & $97.4 \pm 4.7$ & $88.5 \pm 4.0$ \\
\hline \multicolumn{4}{|l|}{ Concentration $(\mu \mathrm{g} / \mathrm{g})$} \\
\hline Injection volume $(\mu 1)$ & 50 & 40 & 40 \\
\hline \multirow[t]{2}{*}{ Column temperature $\left({ }^{\circ} \mathrm{C}\right)$} & 30 & 30 & 35 \\
\hline & \multicolumn{3}{|l|}{ Results } \\
\hline Peak area & $186.9 \pm 0.02$ & $1553.8 \pm 24.7$ & $2482.3 \pm 17.2$ \\
\hline Peak height $(\mathrm{mAu})$ & $7.36 \pm 0.07$ & $100.8 \pm 2.4$ & $259.6 \pm 3.5$ \\
\hline Peak width (min) & $0.447 \pm 0.021$ & $0.0239 \pm 0.004$ & $0.147 \pm 0.002$ \\
\hline $\begin{array}{l}\text { Retention } \\
\text { time (min) }\end{array}$ & $7.55 \pm 0.02$ & $7.71 \pm 0.01$ & $4.72 \pm 0.01$ \\
\hline Theoretical plates & $1590 \pm 147$ & $5784 \pm 163$ & $5657 \pm 145$ \\
\hline $\begin{array}{l}\text { Measured } \\
\text { concentration }\end{array}$ & $118.8 \pm 18.3$ & $91.8 \pm 4.6$ & $83.0 \pm 3.7$ \\
\hline$\%$ Recovery & $130 \pm 15.9$ & $94.3 \pm 1.5$ & $97.2 \pm 4.5$ \\
\hline
\end{tabular}

Values are reported as mean $\pm 1 \mathrm{~s}, n=3$.

$\mathrm{ACN}-\mathrm{H}_{2} \mathrm{O}$ in conjunction with increasing column temperature shortened the elution time while maintaining separation efficiency. The number of theoretical plates is not statistically significantly different for the $60: 40$ ACN- $\mathrm{H}_{2} \mathrm{O}, \quad T=30^{\circ} \mathrm{C}$ and $70: 30$ ACN- $\mathrm{H}_{2} \mathrm{O}, T=35^{\circ} \mathrm{C}$ treatments (Student's $t$-test, $\alpha=0.05, t_{\text {calculated }}=1.01, T_{\text {critical }}=2.78, P\left(t_{\text {calculated }}>\right.$ $\left.T_{\text {critical }}=0.18\right)$ ). A large extraction volume coupled with a small sample size appeared to contribute to excessively high recoveries. Based on these comparisons, it was decided that $2 \times 5.0 \mathrm{ml}$ extractions provided adequate recoveries. Minimizing the number of extraction steps was considered essential in that it was anticipated that the method would be used to run large numbers of fecal samples and the analysis results would be required in a short time frame.

The optimal extraction in terms of time and sensitivity for DNC from feces was $2 \times 5.0 \mathrm{ml} 1: 1$ ACN-DMF, brought to a final volume of $10.00 \mathrm{ml}$. The optimal HPLC conditions were a mobile phase 70:30 ACN-water, $1.0 \mathrm{ml} / \mathrm{min}$ flow-rate, isocratic elution with a column temperature of $35^{\circ} \mathrm{C}$ and an injection volume of $40 \mathrm{ml}$. This method was validated for inter and intra-day recovery efficiencies.

\section{Validation and application to excretion study samples}

Chromatograms for a blank and fortified duck feces sample spiked at $100 \mu \mathrm{g} / \mathrm{g}$ are presented in Fig. 2. DNC elutes at $5.7 \mathrm{~min}$. Additionally, there is no significant chromatographic response at this retention time in the control chromatogram.

Linearity of the detector response or HPLC system was established using duplicate sets of eight standard concentrations. Linearity was established over the range of 0.05 to $20 \mu \mathrm{g} / \mathrm{ml}$. Linear regression analysis of detector response vs. concentration yielded the regression curve:

Response

$=300.654009 * \mathrm{DNC}$ concentration $(\mu \mathrm{g} / \mathrm{ml})$

$$
-8.09947, r^{2}=0.997 \text {. }
$$



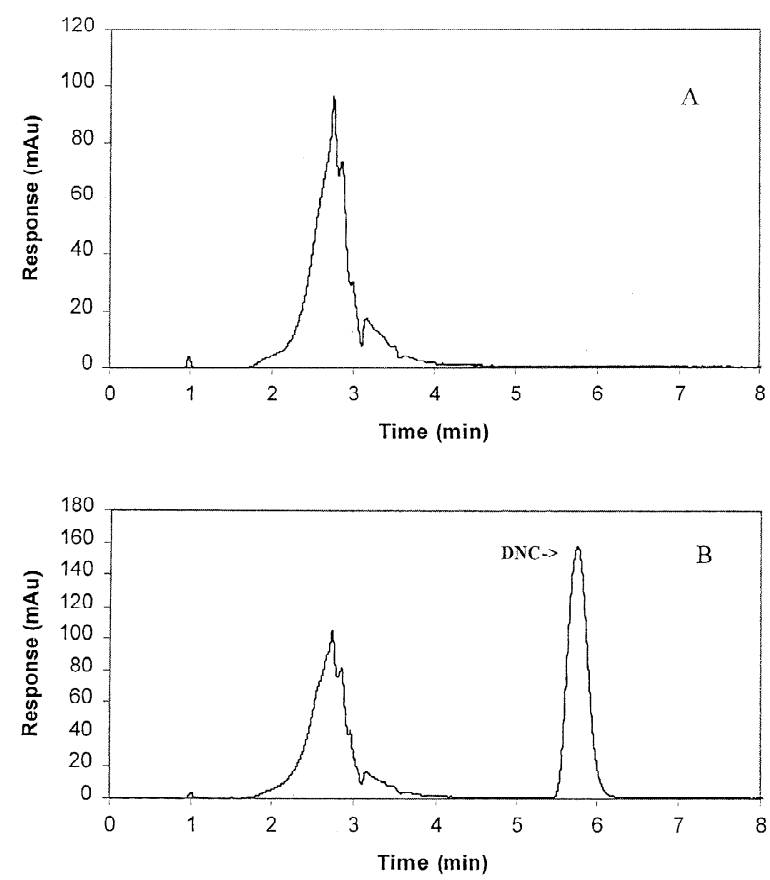

Fig. 2. HPLC chromatograms for an unfortified feces sample (A) and a feces sample fortified at $100 \mu \mathrm{g} / \mathrm{g}$ (B). Chromatograms were collected at $\lambda=347 \mathrm{~nm}$, Keystone $300 \times 4.6 \mathrm{~mm} \mathrm{ODS} / \mathrm{H}$ column, ACN:water $(70: 30 \mathrm{v} / \mathrm{v})$ as mobile phase, at $1.0 \mathrm{ml} / \mathrm{min}$, $40 \mu \mathrm{l}$ injection, $T=35^{\circ} \mathrm{C}$. DNC elutes at approximately $5.7 \mathrm{~min}$.

The intercept was not significantly different than zero, with $T=-0.894, P>T=0.3794$. The instrument level of detection, defined as the concentration of DNC required to produce a signal three times the baseline noise ( $S / N$; measured peak to peak) at 5.7 $\mathrm{min}$ in the control chromatogram was $0.033 \mu \mathrm{g} / \mathrm{ml}$.

The method limit of detection (MLOD), defined as the concentration of DNC in duck feces that would produce a signal, measured peak to peak, three times the baseline noise $(S / N)$ in a feces blank was determined to be $0.077 \mu \mathrm{g} / \mathrm{ml}$. The MLOD was greatly impacted by the source of the LC vials being used during method development. Apparently some of the vials sorbed the DNC and switching to vials from a different vendor has rectified the problem. This MLOD was deemed acceptable as DNC levels this low would not likely have contraceptive effects on waterfowl.

The inter and intra-day recovery efficiencies determined for the method for 3 days are presented in
Table 2

Inter and Intra-day recoveries for the determination of DNC in duck feces

\begin{tabular}{lcc}
\hline & $\begin{array}{l}\text { Inter-day } \\
\text { repeatability }\end{array}$ & $\begin{array}{c}\text { Intra-day } \\
\text { repeatability }\end{array}$ \\
\hline $0.46 \mu \mathrm{g} / \mathrm{g}$ & & \\
Mean $(\mu \mathrm{g} / \mathrm{g})$ & 0.42 & 0.48 \\
$s(\mu \mathrm{g} / \mathrm{g})$ & 0.026 & 0.049 \\
C.V. $(\%)$ & 6.0 & 10.2 \\
Mean recovery \% & 91 & 103 \\
$n$ & 3 & 3 \\
$1.8 \mu \mathrm{g} / \mathrm{g}$ & & \\
Mean $(\mu \mathrm{g} / \mathrm{g})$ & 1.6 & 1.6 \\
$s(\mu \mathrm{g} / \mathrm{g})$ & 0.075 & 0.026 \\
C.V. $(\%)$ & 4.6 & 1.6 \\
Mean recovery $\%$ & 94 & 94 \\
$n$ & 3 & 3 \\
$88.5 \mu \mathrm{g} / \mathrm{g}$ & & 82 \\
Mean $(\mu \mathrm{g} / \mathrm{g})$ & 83 & 3.6 \\
$s(\mu \mathrm{g} / \mathrm{g})$ & 3.7 & 4.4 \\
C.V. $(\%)$ & 4.5 & 92 \\
Mean recovery \% & 97 & 3 \\
$n$ & 3 & \\
\hline
\end{tabular}

Table 2. The inter-day recoveries $(\mu \mathrm{g} / \mathrm{g})$ had coefficients of variation (C.V. $=s /$ mean*100) that ranged from 0.7 to $6.4 \%$ while the intra-day recoveries had C.V.'s that ranged from 1.6 to $10.2 \%$. These were considered acceptable given that the higher C.V.'s were for the lowest fortification level of $0.42 \mu \mathrm{g} / \mathrm{g}$. The percent recovery of the fortification ranged from 91 to $94 \%$ in the inter-day comparison and from 92 to $103 \%$ in the intra-day comparison. These are well within the $\pm 20 \%$ recoveries we consider acceptable for a residue method for a complex matrix.

The method has been successfully applied to a feeding/excretion study of nicarbazin in ducks. Large numbers of samples were analyzed with variable DNC concentrations. Example chromatograms are shown in Fig. 3 that correspond to feces samples collected for a duck fed nicabazin fortified feed at a concentration of $250 \mu \mathrm{g} / \mathrm{g}$. The samples were collected from the same individual on days 7 and 15 of the study with fortified feed having been made available for the 14 days of the study. The levels observed in the feces are $94.4 \mu \mathrm{g} / \mathrm{g}$ on day 7 and $0.301 \mu \mathrm{g} / \mathrm{g}$ DNC on day 15. The birds had not been dosed for 1 day on day 15 , and the low level 

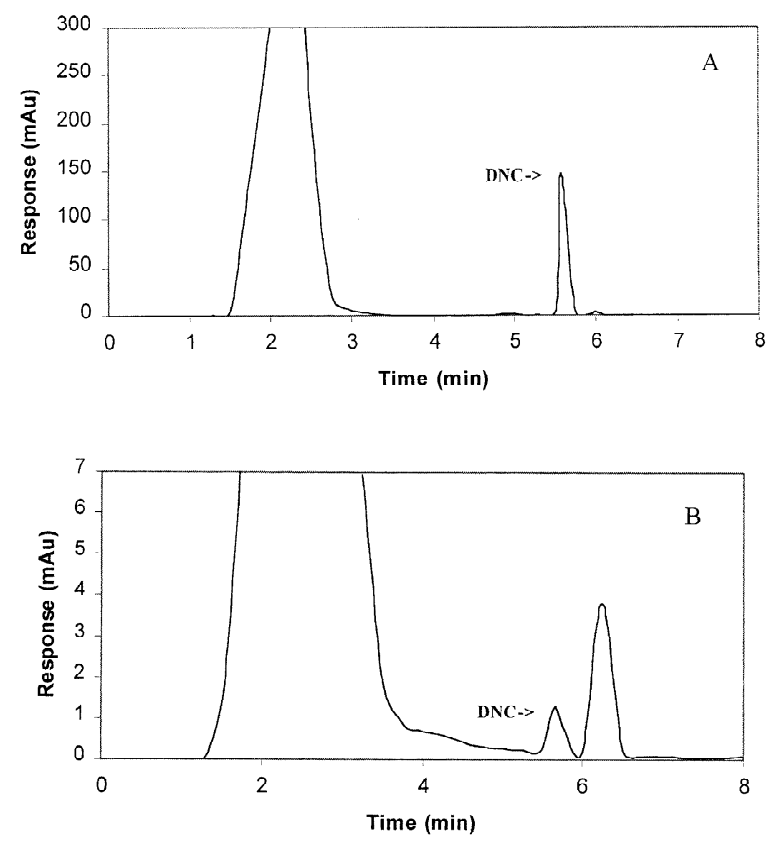

Fig. 3. HPLC chromatograms for duck feces samples analyzed with the method. (A) and (B) are chromatograms for DNC in fecal samples collected from the same duck on days 7 and 15 of the study. Chromatograms were obtained at $\lambda=347 \mathrm{~nm}$, Keystone $300 \times 4.6 \mathrm{~mm}$ ODS $/ \mathrm{H}$ column, ACN:water $(70: 30 \mathrm{v} / \mathrm{v})$ as mobile phase, at $1.0 \mathrm{ml} / \mathrm{min}, 40 \mu \mathrm{l}$ injection, $T=35^{\circ} \mathrm{C}$. DNC elutes at approximately $5.7 \mathrm{~min}$. observed is consistent with reports of rapid excretion of nicarbazin by poultry [12].

\section{References}

[1] H.D. Chapman, Poultry Sci. Res. 5 (1994) 231.

[2] R. Draisci, L. Lucentini, P. Boria, C. Lucarelli, J. Chromatogr. A 697 (1995) 407.

[3] J. Lewis L, T.D. Macey, D.A. Garteiz, J. Assoc. Off. Anal. Chem. 72 (1989) 577.

[4] O.W. Parks, J. Assoc. Off. Anal. Chem. 71 (1988) 778.

[5] J.A. Tarbin, G. Shearer, J. Chromatogr. 613 (1993) 354.

[6] W.J. Blanchflower, P.J. Hughes, D.G. Kennedy, J. AOAC Int. 80 (1997) 1177

[7] M.H. Vertommen, A. Van Der Laan, H.M. Veenendall-Hesselman, J. Chromatogr. 481 (1989) 452.

[8] F.J. Schenk, S.A. Barker, A.R. Long, J. AOAC Int. 75 (1992) 659.

[9] A. Cannavan, G. Ball, D.G. Kennedy, The Analyst 124 (1999) 1431.

[10] T.D. Macy, A. Loh, J. Assoc. Off. Anal. Chem. 67 (1984) 1115.

[11] J.A. Hurlbut, C.T. Nightengale, R.G. Burkepile, J. Assoc. Off. Anal. Chem. 68 (1985) 596

[12] WHO Technical Report Series 888, Evaluation of Certain Veternary Drug Residues in Food, 1999, pp. 66-93. 